\title{
Simulation of planetary waves and their influence on the zonally averaged circulation in the middle atmosphere
}

\author{
Alexander Pogoreltsev \\ Institute of Ionosphere, Ministry of Science and Higher Education, Almaty, 480068, Republic of Kazakstan
}

(Received July 14, 1998; Revised April 9, 1999; Accepted April 9, 1999)

\begin{abstract}
A linearized numerical model is used to simulate the propagation of stationary planetary waves through the stratosphere and mesosphere into the lower thermosphere. Wave forcing at the lower boundary has been specified by the perturbation of the geopotential height for January. The dependence of planetary wave structure on the zonally averaged wind is investigated through the analysis of results of simulation with different background wind distributions. The global model of stationary planetary waves has been modified to simulate traveling planetary waves, and the spectrum of resonant planetary modes has been obtained by forcing the model with a periodic perturbation of the vertical velocity near the surface. Wave-activity density, Eliassen-Palm flux, and its divergence are used as a diagnostics of wave propagation and wave-mean flow interaction. It is found that planetary waves can provide substantial acceleration of the mean flow which is comparable to that one associated with gravity wave and atmospheric tide breaking and/or saturation. Results of numerical simulation are compared with the climatological model of stationary planetary waves in the stratosphere and with the preliminary results of wind observations using WINDII instrument on the UARS.
\end{abstract}

\section{Introduction}

Analysis of the results obtained by the Wind Imaging Interferometer (WINDII) and High Resolution Doppler Imager (HRDI) on the Upper Atmosphere Research Satellite (UARS) shows a presence of the strong large-scale longitudinal variations of the emission rates and horizontal winds in the mesosphere and lower thermosphere (Shepherd et al., 1993; Smith, 1997), which were interpreted as manifestation of planetary waves (PWs). Besides, the main purpose of the PSMOS project is the establishment of a ground-based mesopause observing system for the investigation of planetary scale disturbances, and the purpose of present paper is to show some results of the simulation of PWs in the middle atmosphere and to discuss a possibility of the observation of these waves by satellite and ground-based equipment. The comparison of numerical results with the experimental data will be made and the contribution of PWs to the zonally averaged dynamics of mesopause region will be considered.

\section{Model Formulation}

The initial set of the equations describing the disturbances and zonally averaged state can be written as follows (Boyd, 1976; Andrews, 1985)

$$
\begin{gathered}
(\bar{u}-c) u_{\lambda}^{\prime} /(a \cos \varphi)-f_{1} v^{\prime}+\bar{u}_{z} w^{\prime}+\phi_{\lambda}^{\prime} /(a \cos \varphi)=X^{\prime} \\
(\bar{u}-c) v_{\lambda}^{\prime} /(a \cos \varphi)+f_{2} u^{\prime}+\phi_{\varphi}^{\prime} / a=Y^{\prime} \\
\phi_{z}^{\prime}=R \theta^{\prime} \exp (-\kappa z / H) / H \\
u_{\lambda}^{\prime} /(a \cos \varphi)+\left(\cos \varphi v^{\prime}\right)_{\varphi} /(a \cos \varphi)+\left(\rho_{0} w^{\prime}\right)_{z} / \rho_{0}=0
\end{gathered}
$$

Copy right $(\mathcal{C}$ The Society of Geomagnetism and Earth, Planetary and Space Sciences (SGEPSS); The Seismological Society of Japan; The Volcanological Society of Japan; The Geodetic Society of Japan; The Japanese Society for Planetary Sciences.

$$
\begin{gathered}
(\bar{u}-c) \theta_{\lambda}^{\prime} /(a \cos \varphi)+\bar{\theta}_{\varphi} v^{\prime} / a+\bar{\theta}_{z} w^{\prime}=Q^{\prime}, \\
\bar{u}_{t}-f_{1} \bar{v}^{*}+\bar{u}_{z} \bar{w}^{*}=\bar{X}+\nabla \cdot \mathbf{F} /\left(\rho_{0} a \cos \varphi\right), \\
(f+\bar{u} \tan \varphi / a) \bar{u}+\bar{\phi}_{\varphi} / a=\bar{G}, \\
\bar{\phi}_{z}=R \bar{\theta} \exp (-\kappa z / H) / H, \\
\left(\cos \varphi \bar{v}^{*}\right)_{\varphi} /(a \cos \varphi)+\left(\rho_{0} \bar{w}^{*}\right)_{z} / \rho_{0}=0, \\
\bar{\theta}_{t}+\bar{\theta}_{\varphi} \bar{v}^{*} / a+\bar{\theta}_{z} \bar{w}^{*}=\bar{Q}-\left(\rho_{0} \nabla \bar{\theta} \cdot \overline{\mathbf{v}}^{\prime} \theta^{\prime} / \bar{\theta}_{z}\right)_{z} / \rho_{0} .
\end{gathered}
$$

Here $\lambda$ is longitude, $\varphi$ is latitude, $z=-H \ln \left(p / p_{\mathrm{s}}\right)$ is the vertical coordinate, where $p$ is pressure, $p_{\mathrm{s}}=$ const is a standard reference pressure, $H=$ const is the scale height; $u, v$, and $w$ are the corresponding velocities, $\phi$ denotes the geopotential, and $\theta$ the potential temperature; $R$ is the gas constant for dry air, $\kappa=R / c_{\mathrm{p}}, c_{\mathrm{p}}$ is the specific heat at constant pressure; $X, Y$ are the unspecified horizontal components of friction or other nonconservative mechanical forcing, $Q$ is the diabatic heating term; $\rho_{0}(z)=\rho_{\mathrm{s}} \exp (-z / H)$ is a reference density profile, $\rho_{\mathrm{s}}=$ const; $f_{1}=f+\bar{u} \tan \varphi / a-\bar{u}_{\varphi} / a$, $f_{2}=f+2 \bar{u} \tan \varphi / a, f=2 \Omega \sin \varphi$ is the Coriolis parameter; $\Omega$ and $a$ are the Earth's rotation rate and radius; $\mathbf{F}=\left(0, F^{(\varphi)}, F^{(z)}\right)$ is the Eliassen-Palm (EP) flux vector, $\bar{G}$ represents all the terms that lead to departures from the gradient wind balance between $\bar{\phi}_{\varphi}$ and $\bar{u} ; \bar{v}^{*}$ and $\bar{w}^{*}$ define the residual meridional circulation velocities. In Eqs. (1)-(10) an overbar denotes the zonally averaged values, the disturbance is denoted by a prime; the subscripts $\lambda, \varphi, z, t$ denote corresponding derivatives.

We assume the disturbances in Eqs. (1)-(10) to be a sum of zonal harmonics, i.e., $q^{\prime}(\lambda, \varphi, z, t)=\operatorname{Re} \sum_{m} q_{m}^{\prime}(\varphi, z)$ $\exp [i(m \lambda-\omega t)]$, where $q_{m}^{\prime}$ is the complex amplitude and $m$ is the zonal wavenumber. It is necessary to note that Eqs. (1)-(5) are the linearized set of equations for disturbances, 
and that they apply for a single zonal harmonic with phase speed $c$.

The formulation of the boundary-value problem for simulation the latitude height structure of the planetary scale disturbances and the numerical method of the solution were described in the paper Pogoreltsev and Sukhanova (1993), and here we will only present and discuss the results of the simulations with this model. However, it is necessary to note that the simplification of the initial set of equations for disturbances based on the scale analysis (by assuming a large Richardson and a small Rossby numbers (Pogoreltsev, 1996)) are not justified in the case of inertia-gravity PWs (Salby, 1980) (for instance, the 2- and 5-day travelling PWs), and in present paper we will consider the solution of exact primitive set of Eqs. (1)-(5).

Following Pogoreltsev (1996), we resolve (1) and (2) with respect to $v^{\prime}$ and introduce a new function $\psi^{\prime}$ as follows

$$
\begin{array}{r}
\psi^{\prime}=\frac{a \cos \varphi}{i \sigma_{\mathrm{R}}} v^{\prime}=\frac{a \cos \varphi}{i \sigma_{\mathrm{R}}\left(f_{1} f_{2}-\sigma_{\mathrm{R}}^{2}\right)}\left[-i \sigma_{\mathrm{R}} \phi_{\varphi}^{\prime} / a\right. \\
\left.+f_{2} i m \phi^{\prime} /(a \cos \varphi)+i f_{2} \bar{u}_{z} w^{\prime}\right],
\end{array}
$$

i.e.,

$$
v^{\prime}=i \sigma_{\mathrm{R}} \psi^{\prime} /(a \cos \varphi),
$$

where $\sigma_{\mathrm{R}}=m \bar{u} / a \cos \varphi-\omega-i \beta_{\mathrm{R}}, \beta_{\mathrm{R}}$ is the Rayleigh friction coefficient.

Solving (5) with respect to $w^{\prime}$, and eliminating $v^{\prime}$ using (16), we obtain

$$
w^{\prime}=\frac{1}{N^{2}}\left[i \sigma_{\mathrm{R}} f_{2} \bar{u}_{z} \psi^{\prime} /(a \cos \varphi)-i \sigma_{\mathrm{N}} \phi_{z}^{\prime}\right]
$$

where $\sigma_{\mathrm{N}}=m \bar{u} / a \cos \varphi-\omega-i \alpha_{\mathrm{N}}, \alpha_{\mathrm{N}}$ is the Newtonian cooling coefficient. Account being taken of (3) and the following expressions $\bar{\theta}_{\varphi} / a=-\bar{u}_{z} f H \exp (-\kappa z / H) / R, \bar{\theta}_{z}=$ $N^{2} H \exp (-\kappa z / H) / R$, where $N^{2}=R\left(T_{0 z}+\kappa T_{0}\right) / H$ is the Brunt-Väisälä frequency squared, $T_{0}$ is the background temperature. The dissipative processes were parameterized in the form of Rayleigh friction $\left(X^{\prime}=-\beta_{\mathrm{R}} u^{\prime}, Y^{\prime}=-\beta_{\mathrm{R}} v^{\prime}\right)$ and Newtonian cooling $\left(Q^{\prime}=-\alpha_{\mathrm{N}} \theta^{\prime}\right)$.

Then, using (12) and (13), Eq. (1) can be resolved with respect to the perturbation of the zonal velocity

$$
u^{\prime}=\frac{1}{a \cos \varphi}\left[\left(f_{1}-f_{2} \frac{\bar{u}_{z}^{2}}{N^{2}}\right) \psi^{\prime}-\frac{m}{\sigma_{\mathrm{R}}} \phi^{\prime}\right]+\frac{\bar{u}_{z} \sigma_{\mathrm{N}}}{\sigma_{\mathrm{R}} N^{2}} \phi_{z}^{\prime} .
$$

Substituting (13) into (11), and solving the later with respect to $\phi_{\varphi}^{\prime}$, we obtain

$\phi_{\varphi}^{\prime}=\frac{m f_{2}}{\sigma_{\mathrm{R}} \cos \varphi} \phi^{\prime}-\frac{a f_{2} \bar{u}_{z} \sigma_{\mathrm{N}}}{\sigma_{\mathrm{R}} N^{2}} \phi_{z}^{\prime}-\frac{f_{1} f_{2}-\sigma_{\mathrm{R}}^{2}-f_{2}^{2} \bar{u}_{z}^{2} / N^{2}}{\cos \varphi} \psi^{\prime}$.

Substituting $u^{\prime}(14)$ and $v^{\prime}$ (12) into (4), and eliminating $w^{\prime}$ using (13), we obtain the following equation

$$
\begin{gathered}
\psi_{\varphi}^{\prime}=-\frac{m f_{2}\left(1-\bar{u}_{z}^{2} / N^{2}\right)}{\sigma_{\mathrm{R}} \cos \varphi} \psi^{\prime}+\frac{i}{\sigma_{\mathrm{R}}} \frac{\partial \beta_{\mathrm{R}}}{\partial \varphi} \psi^{\prime} \\
+\frac{m^{2}}{\sigma_{\mathrm{R}}^{2} \cos \varphi} \phi^{\prime}-\frac{m a \bar{u}_{z} \sigma_{\mathrm{N}}}{\sigma_{\mathrm{R}}^{2} N^{2}} \phi_{z}^{\prime}+\frac{i a^{2} \cos \varphi}{\sigma_{\mathrm{R}} \rho_{0}} \\
\times \frac{\partial}{\partial z}\left\{\frac{\rho_{0}}{N^{2}}\left[i \sigma_{\mathrm{R}} f_{2} \bar{u}_{z} \psi^{\prime} /(a \cos \varphi)-i \sigma_{\mathrm{N}} \phi_{z}^{\prime}\right]\right\},
\end{gathered}
$$

account being taken of $\partial \sigma_{\mathrm{R}} / \partial \varphi=m\left(f_{2}-f_{1}\right) / \cos \varphi-$ $i \partial \beta_{\mathrm{R}} / \partial \varphi$

The set of Eqs. (15) and (16) is very similar to those considered in Pogoreltsev and Sukhanova (1993), and the numerical method described in this paper can be applied to the solution of the boundary value problem with small modifications.

\section{The Background State}

The numerical simulations of the global structure of planetary waves were carried out for the climatic conditions of the Northern hemisphere winter. The background temperature was taken from the MSIS-90 model (Hedin, 1991). The vertical profile of $T_{0}(z)$ is shown in Fig. 1. The simulations that we discuss were performed for the atmosphere with scale height $H=7 \mathrm{~km}$ using the vertical step $\Delta z=H / 4$.

To simulate the global structure of SPWs, we used three models of the background wind for January conditions

1) HWM-93 model (Hedin et al., 1996);

2) In altitude region between 90 and $120 \mathrm{~km}$ we used an empirical model of zonal wind based on the WINDII data (Wang et al., 1997).

The background wind distributions in the HWM-93 and WINDII models are shown in Figs. 2 and 3. One can see that in these models the westerlies over equator in the mesosphere are absent. However, the direct measurements by the HRDI for January 1992 through June 1993 show the westerlies over equator up to the $90 \mathrm{~km}$ in winter (Lieberman et al., 1993; Lieberman and Riggin, 1997). To investigate the effect of the mesospheric westerlies over equator on the propagation of the PWs, we used

3) MODIFIED model, which was defined as follows

$$
\begin{aligned}
\bar{u}= & \bar{u}(\text { WINDII }) \\
& +30 \exp \left[-\left(\frac{z-75}{15}\right)^{2}\right] \exp \left[-\left(\frac{\varphi}{30}\right)^{2}\right] .
\end{aligned}
$$

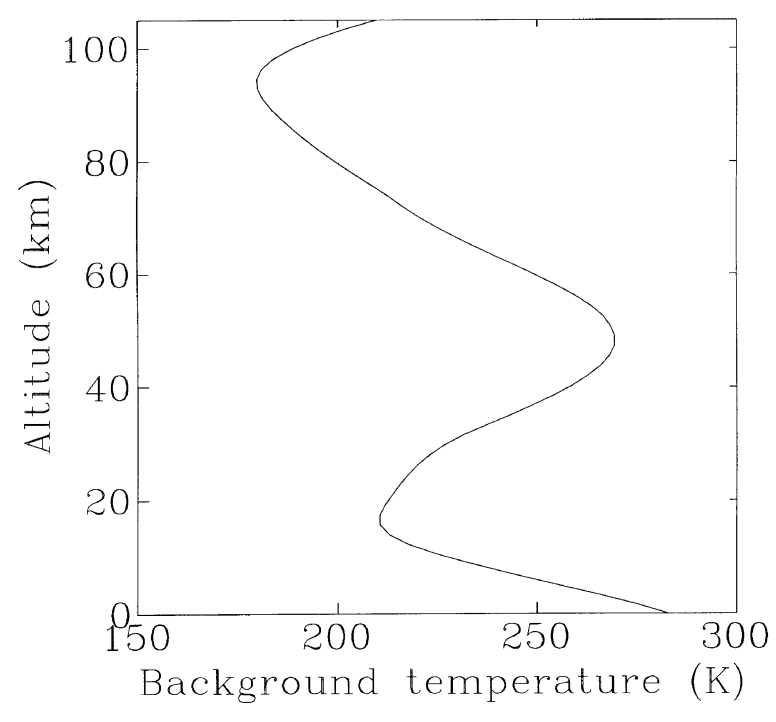

Fig. 1. The vertical profile of the background temperature. 


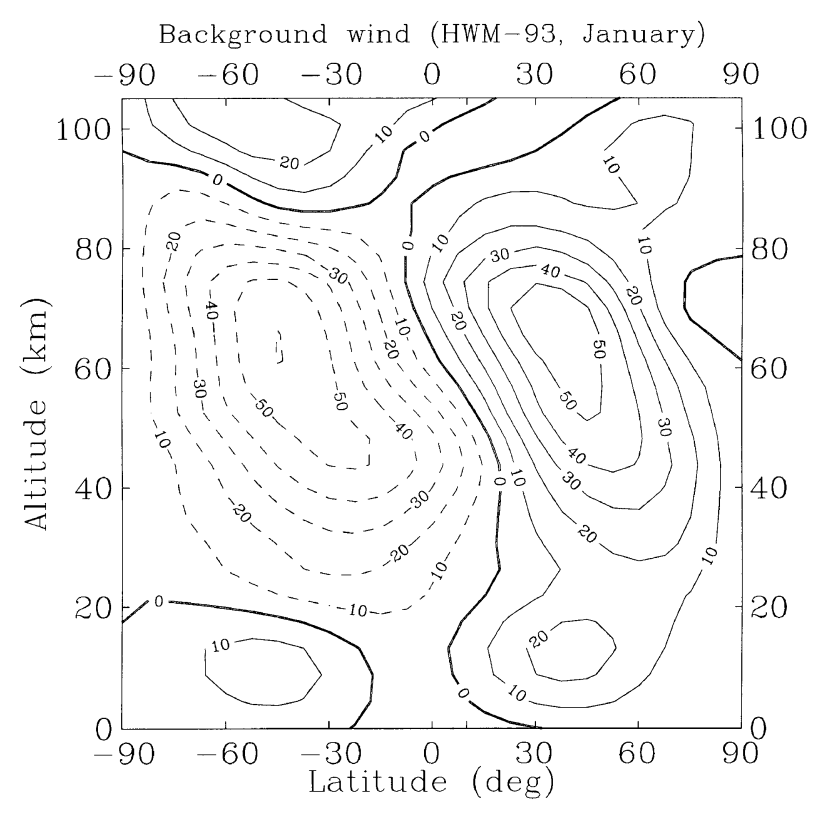

Fig. 2. Meridional contours of background zonal wind $(\mathrm{m} / \mathrm{s})$ for HWM-93 model, solid—westerlies, dashed-easterlies. January conditions.

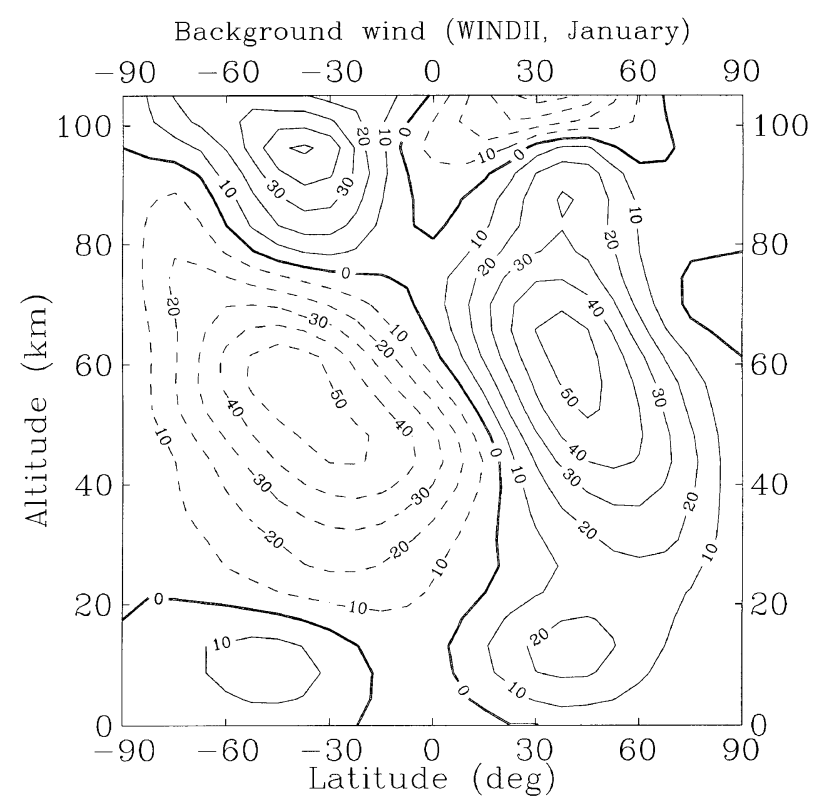

Fig. 3. As in Fig. 2, for WINDII model.

The distribution of the background wind for the MODIFIED model is shown in Fig. 4.

\section{Dissipation Parameters}

The dissipative processes were parameterized in the form of Rayleigh friction and Newtonian cooling with coefficients $\beta_{\mathrm{R}}(z, \varphi)$ and $\alpha_{\mathrm{N}}(z)$. To avoid the numerical instability of the solution near the critical surfaces, we introduce a localized effective Rayleigh friction coefficient in these regions

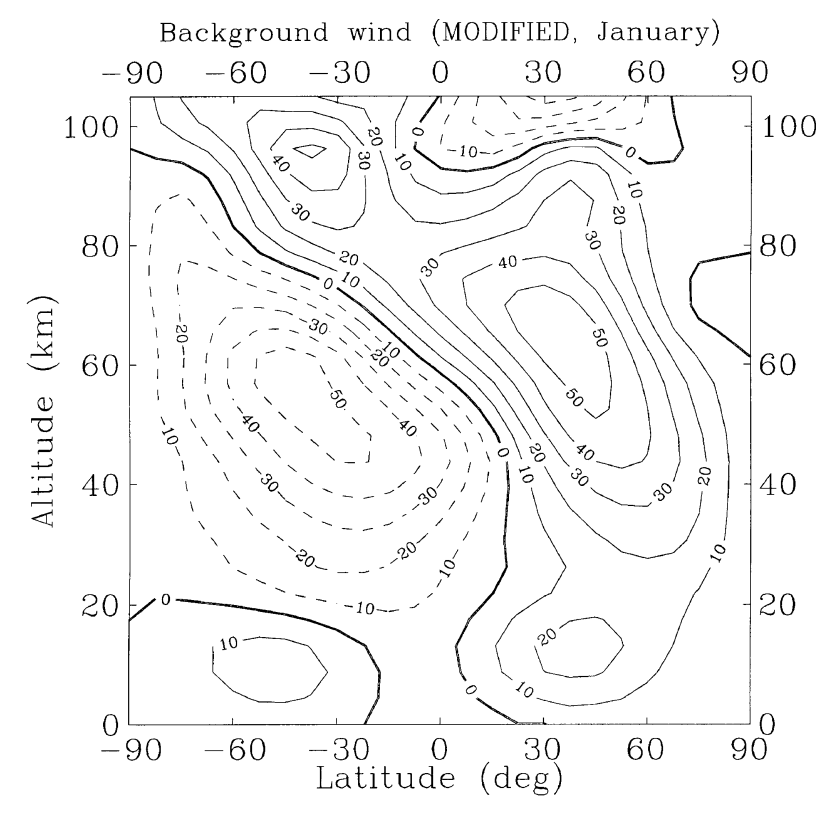

Fig. 4. As in Fig. 2, for MODIFIED model.

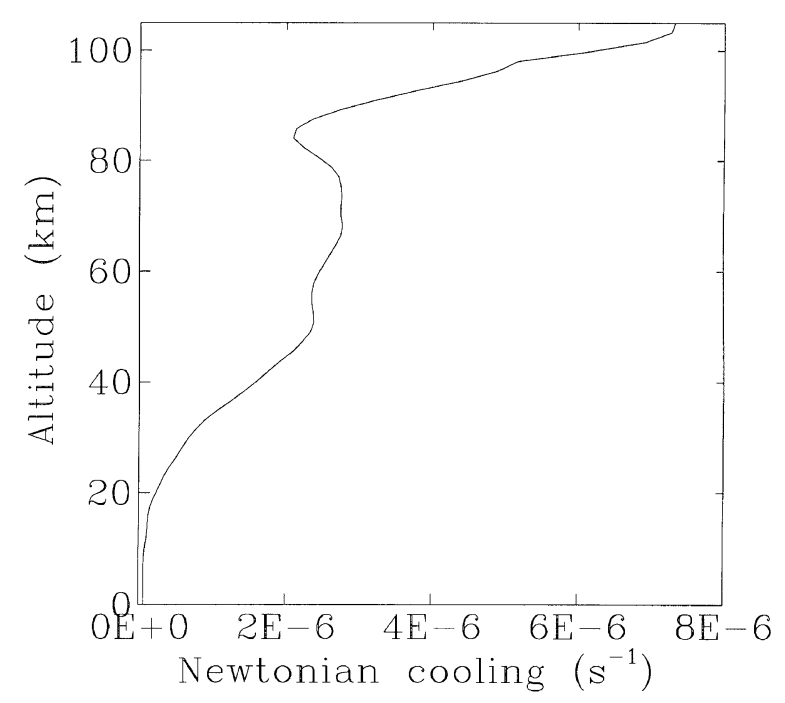

Fig. 5. The vertical profile of the radiative damping rate.

$\beta_{\mathrm{R}}(z, \varphi)=\beta_{\mathrm{R} 0}+\left(m \beta_{\mathrm{R} m}-\beta_{\mathrm{R} 0}\right) \exp \left[-\left(\frac{\bar{u}-c}{a \cos \varphi \beta_{\mathrm{R} m}}\right)^{2}\right]$,

where $\beta_{\mathrm{R} 0}=10^{-6} \mathrm{~s}^{-1}, \beta_{\mathrm{R} m}=3 \cdot 10^{-6} \mathrm{~s}^{-1}$. For Newtonian cooling we used the parameterization of damping rate in the cool-to-space limit given by Zhu (1993). Above $120 \mathrm{~km}$ the infrared radiation resulting from $5.3 \mu \mathrm{m}$ nitric oxide band plays the main role in the lower thermosphere heat balance, and we used the formula given by Kockarts (1980) to calculate the damping rate in the thermosphere. The resulting Newtonian cooling coefficient is presented in Fig. 5. 


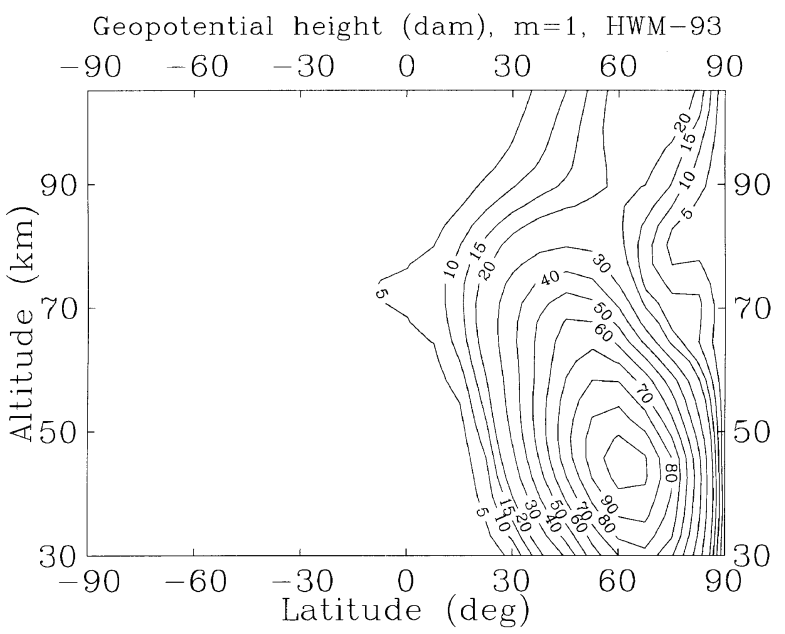

Fig. 6. Latitude-height section of amplitude (dam) for the perturbation of the geopotential height in SPW with $m=1$ and background wind from HWM-93 model.

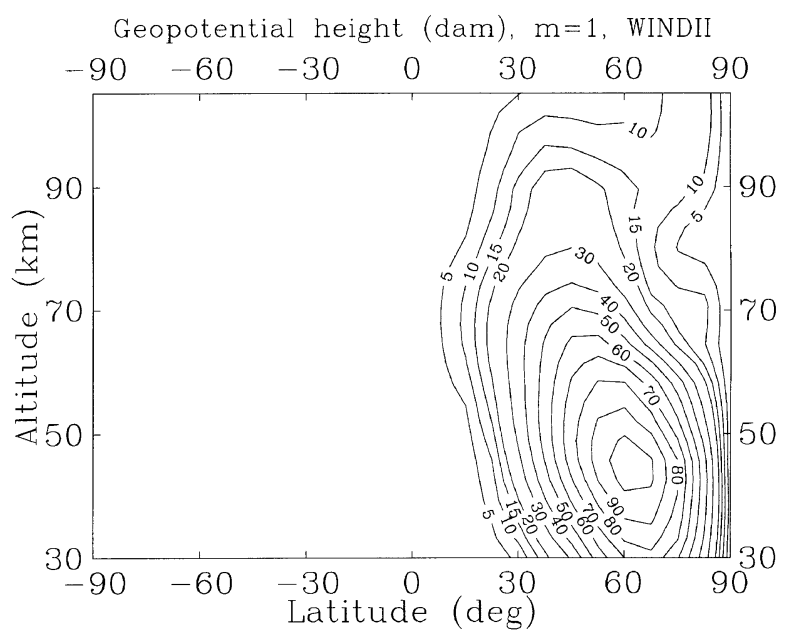

Fig. 7. As in Fig. 6, for WINDII model.

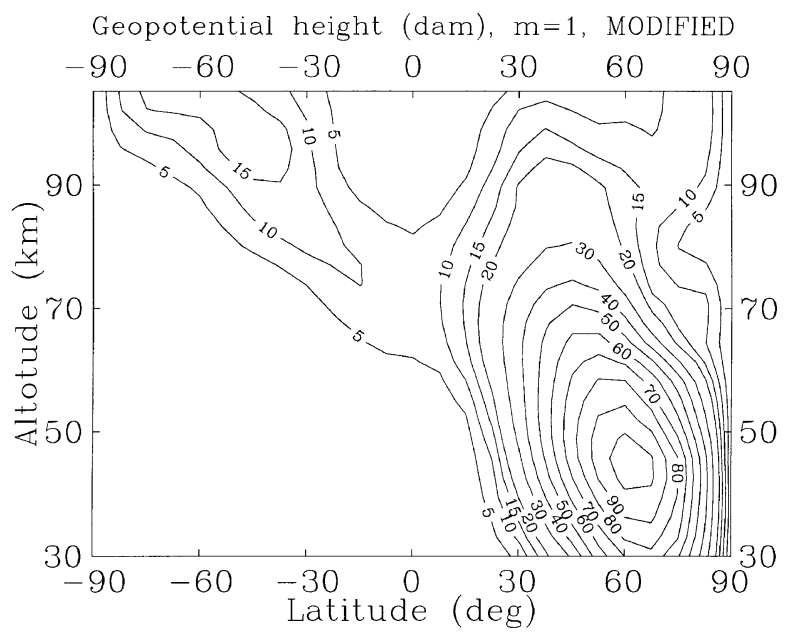

Fig. 8. As in Fig. 6, for MODIFIED model.

\section{Boundary Conditions}

To simulate the global structure of stationary planetary waves (SPW) with zonal wave number $m=1$, the amplitudes and phases of geopotential height perturbations at the level $18.55 \mathrm{mb}(z=28 \mathrm{~km})$ taken for January conditions from CIRA-86 climatic model (Barnett and Corney, 1985) were set as a low boundary condition. The lower boundary condition for traveling PWs will be discussed later, when we will consider the resonant response of the atmosphere to lower boundary forcing. The perturbation of the geopotential at the upper boundary which is set at $140 \mathrm{~km}$ was taken to be equal zero. This upper boundary condition leads to the PWs reflection. However, due to strong dissipation in the lower thermosphere, the influence of this reflection becomes negligible at short distances from the upper boundary.

\section{The Influence of Background Wind Distribution on SPW}

The results of simulation of the stationary planetary wave with zonal wave number $m=1$ in a form of isolines of amplitude of the geopotential height perturbation are shown in Figs. 6-8 for HWM-93, WINDII, and MODIFIED models of the background wind. One can see that in the cases of the HWM-93 and WINDII models SPW propagates mainly into the high latitude region of the Northern hemisphere and then dissipates at the altitudes of the lower thermosphere (see Figs. 6 and 7). In the case of MODIFIED model there is a penetration of SPW into the Southern hemisphere across the equator through the mesospheric westerlies. In result the amplitudes of the geopotential height perturbations in the SPW with $m=1$ are comparable in the lower thermosphere of the winter and summer hemispheres. The comparison Figs. 6-8 with results obtained by Pogoreltsev (1996) using CIRA86 zonal mean wind model (Chandra et al., 1990) shows that in our case the latitudinal structure of the geopotential height perturbation is more smooth (the maximum at $75^{\circ} \mathrm{N}$ in the mesopause region is absent, see figure 3 in Pogoreltsev, 1996). It seems that the main reason for this discrepancy is the strong latitudinal smoothing of the zonal mean wind due to including only limited set of the vector spherical harmonics in the analytical empirical horizontal wind models (Hedin et al., 1991; Wang et al., 1997).

\section{Comparison of the Computations and Observa- tions}

The vertical structure of the geopotential height perturbation in SPW with $m=1$ at the latitude $60^{\circ} \mathrm{N}$ for MODIFIED background wind model is shown in Fig. 9. Dotted lines show the vertical profiles of the amplitude and phase taken from empirical model of SPW (Barnett and Corney, 1985). The comparison of the results of simulation (solid lines) with observations shows good agreement.

The latitudinal dependencies of the amplitude and phase of the meridional wind perturbation in SPW with zonal wave number $m=1$ at the altitude $z=90 \mathrm{~km}$ are shown in Fig. 10. Dotted lines show the results obtained from WINDII data averaged over period 1992-1996 (Wang, D. Y., private communication). Solid lines show the results of simulation with the MODIFIED background wind model. One can see that the latitudinal structure of the amplitude does not 
Geopotential height $(60 \mathrm{~N}), \mathrm{m}=1$

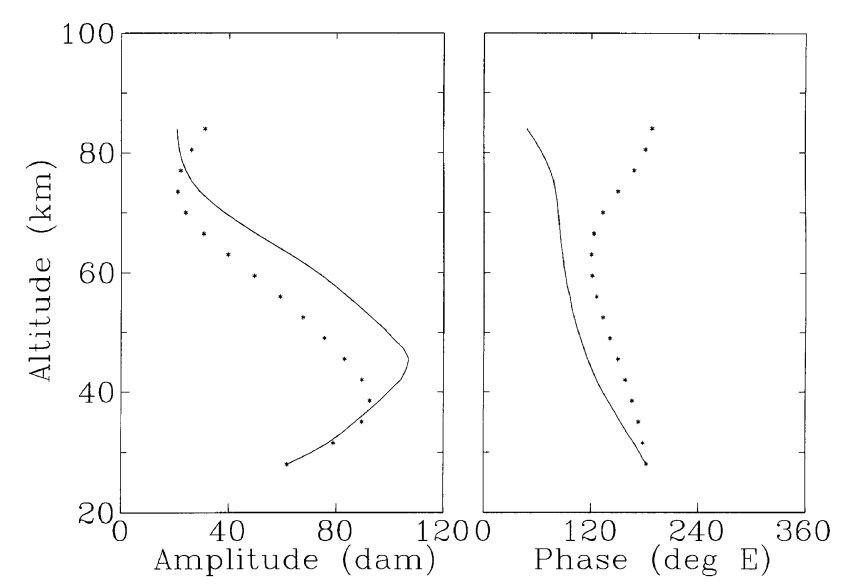

Fig. 9. The vertical profiles of the amplitude and phase (the position of ridges) of the geopotential height perturbation in SPW with $m=1$ at the latitude $60^{\circ} \mathrm{N}$. Dotted lines show the results from empirical model CIRA-85.

Meridional wind, $\mathrm{m}=1 \quad(\mathrm{z}=90 \mathrm{~km})$

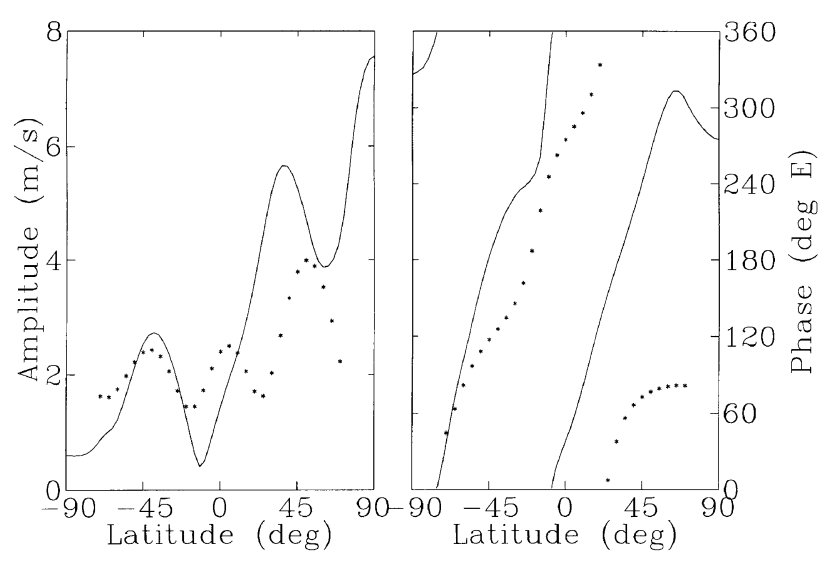

Fig. 10. Latitudinal dependencies of the amplitude and phase of the meridional wind perturbation in SPW with $m=1$ at the altitude $z=90 \mathrm{~km}$. Dotted lines show the results obtained from WINDII data averaged over period 1992-1996 (Wang, D. Y., private communication).

show good agreement between WINDII observations and solution. Perhaps the reason for this discrepancy is the latitudinal smoothing of the background wind in the analytical empirical horizontal wind models (Hedin et al., 1991; Wang et al., 1997). However, the latitudinal behavior of the phase (westward slope) shows good agreement between WINDII observations and solution. It is necessary to note that westward slope of the phase, when we move from the Northern to Southern hemisphere, indicates the cross equatorial SPW propagation, and this result supports our assumption that in winter there are the westerlies over the equator in the mesosphere.

\section{Response of the Atmosphere to the Lower Boundary Forcing}

The model of the global structure of SPW (Pogoreltsev and Sukhanova, 1993) was modified to simulate the spectral atmospheric response to the symmetric and asymmetric forcing by the perturbation of the vertical velocity at the lower boundary. This problem is similar to the problem which was considered by Schoeberl and Clark (1980). However, there are some reasons to reconsider this question once more. Schoeberl and Clark (1980) used the quasi-geostrophic vorticity equation for the simulation of the structure of PW. Kirushov (1988) investigated the eigenvalues and eigenfunctions of the latitudinal structure operator of PW under quasigeostrophic approximation, and it has been shown that the spectrum becomes quasi-confluent and symmetric modes coincide with asymmetric ones with the exception of the sign in another hemisphere when the Rayleigh friction coefficient tends to zero. In other words, we have the complete set of the eigenfunctions in each hemisphere separately, and the Northern and Southern hemispheres do not interact in this case. In result low frequency responses of the atmosphere to the symmetric and asymmetric forcing are very similar (see figure 2 in Schoeberl and Clark, 1980). In the case of primitive set of equations the responses become noticeably different. This problem was investigated by Salby (1981a), and it has been shown that the background wind shears cause the spectral broadening and shifting of the resonant responses. However, it seems that strong spectral broadening obtained by Salby (1981a) is the consequence of the low latitudinal resolution and small dissipation. Lindzen and Blake (1972) showed that realistic dissipation mechanisms suppress the atmospheric response, and that the effect increases with the period of the wave.

To investigate the sensitivity of the atmospheric response to lower boundary forcing, we specified the following boundary conditions. For the symmetric forcing we used $\tilde{w}^{*}(z=$ $0)=\tilde{w}_{0}^{*} \cos 2 \vartheta$, and for asymmetric forcing $\tilde{w}^{*}(z=0)=$ $\tilde{w}_{0}^{*} \cos \vartheta$, where $\tilde{w}^{*}=w^{*} 2 \Omega a / g H \cos ^{m} \varphi, w^{*}=w^{\prime}-$ $i \omega \phi^{\prime} / g$ is the analog of the vertical velocity in the geometric coordinates, $\vartheta=\pi / 2-\varphi$ is co-latitude, and $\tilde{w}_{0}=10^{-5}$. It is necessary to note here that all calculations connected with traveling PWs were made with the HWM-93 model of the background wind for January conditions.

The amplitude response of the model to the lower boundary forcing for westward PWs with $m=1$ as function of the period are shown in Fig. 11. Here we define the response as follows

$$
\text { Response }=\frac{1}{N} \sum_{i, j}^{\mathrm{All}}\left|\phi_{i j}^{\prime}\right| \exp \left(-z_{i} / 2 H\right),
$$

where $N$ is a number of grid points. One can see from this figure that there are well defined resonant responses at the periods about 5 and 16 days for symmetric, and at the period about 10 days for asymmetric forcing. The latitudinal structures of the geopotential height perturbations in the 10and the 16-day PWs at the altitude $z=7 \mathrm{~km}$ are shown in Fig. 12. This figure shows that these waves can be identified with first asymmetric $(1,2)$ and second symmetric $(1,3)$ normal atmospheric modes in the nomenclature of LonguetHiggins (1968). By analogy the 5-day PW can be identified 


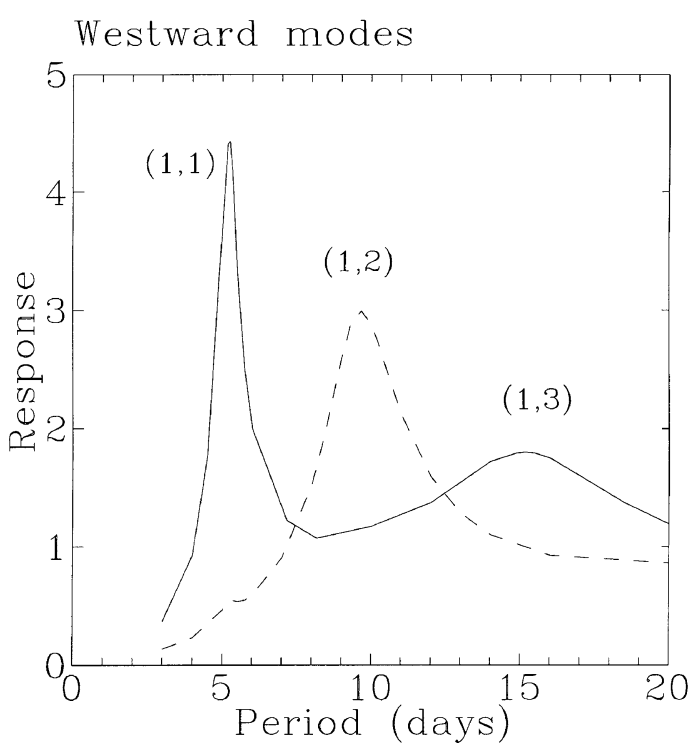

Fig. 11. Response to the symmetric (solid) and asymmetric (dashed) forcing for the westward PWs with $m=1$.

Geopotential height, 10-day PW, $\mathrm{z}=7 \mathrm{~km}$

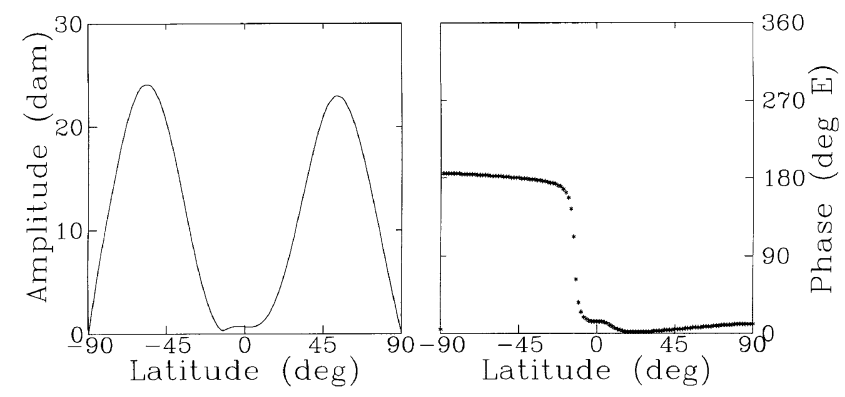

Geopotential height, 16-day PW, $\mathrm{z}=7 \mathrm{~km}$

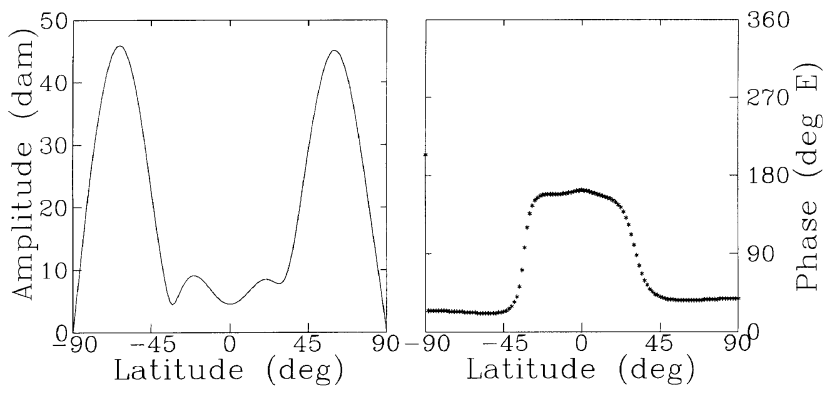

Fig. 12. The latitudinal structure of the geopotential height perturbations in the 10- and 16-day PWs at altitude $7 \mathrm{~km}$.

with first symmetric mode $(1,1)$. The amplitude response of the model to the lower boundary forcing for the westward PW with $m=2$ is shown in Fig. 13. It is easy to identify the maxima in this figure with first symmetric $(2,1)$ and first asymmetric $(2,2)$ normal modes with the periods about 4 and 7 days, respectively. The second symmetric mode for PW with $m=2$ does not develop due to strong dissipation.

To reproduce the realistic conditions, we calibrate the solution in our model using the measured geopotential height am-

\section{Westward modes}

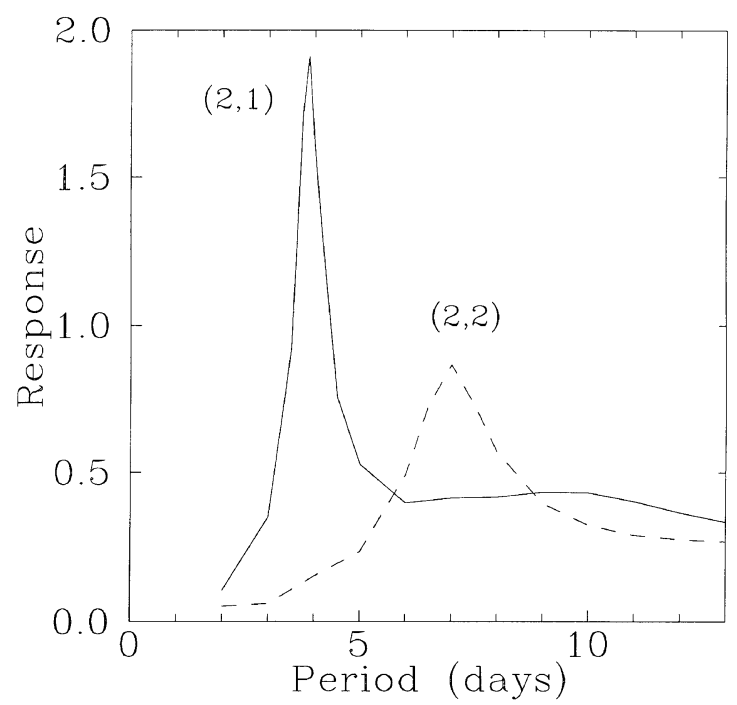

Fig. 13. Response to the symmetric (solid) and asymmetric (dashed) forcing for the westward PWs with $m=2$.

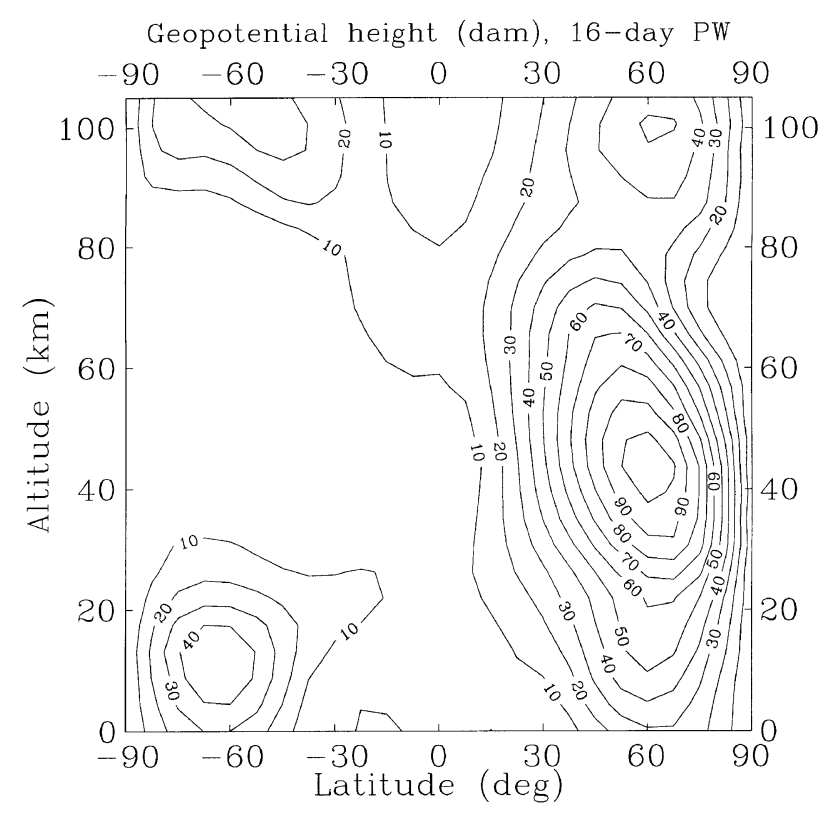

Fig. 14. Latitude-height section of amplitude (dam) for the perturbation of the geopotential height in 16-day PW.

plitude of the 16-day PW in stratosphere averaged over January 10-22, 1979 - the maximum is about 100 dam (Smith, 1985). The latitude-altitude structure of the geopotential height amplitude for the 16-day PW is shown in Fig. 14. One can see that this wave propagates from winter stratosphere into the summer lower thermosphere across the equator. This result is similar to the result obtained by Forbes et al. (1995) using the Global Scale Wave Model-GSWM (Hagan et al., 1995). The direct comparison of our results with the ones obtained using the GSWM is impossible because the dif- 
ferent background wind models were used for simulation. However, it is necessary to note that the propagation of the 16-day PW across the equator without the westerlies in the mesosphere at low latitudes is more effective in our case. We calibrate the 10-day PW solution by similar way, assuming that in the mesopause region this wave has the amplitude comparable with the amplitude of the 16-day PW, and the latitude-altitude structure of the 10-day PW is shown in Fig. 15. The latitudinal structures of the geopotential height perturbations in the 10- and 16-day PWs at the altitude $z=96$ $\mathrm{km}$ are shown in Fig. 16. One can see from this figure that the latitudinal changes in these waves are very similar, and there are westward slopes of phases from Northern to Southern hemisphere for both of waves. These slopes indicate the propagation of PW from winter into summer hemisphere across the equator. We cannot identify the 10- and 16-day PWs in the mesopause region with the normal atmospheric modes as, for instance, in the troposphere (see Fig. 12), and it is possible to make a conclusion that the latitudinal structure of these waves in the middle and upper atmosphere depends mainly on the distribution of the background wind, and does not depend on the latitudinal structure of the lower boundary source. The structures of the amplitude of zonal wind, meridional wind, and temperature perturbations due to the 16-day PW are shown in Figs. 17-19. These figures show that there exist substantial $( \pm 15 \mathrm{~m} / \mathrm{s})$ variations of the zonal wind in the mesopause region conditioned by the 16-day wave. The variations of the meridional wind are smaller by a factor of 2 . These values are in a good agreement with the experimental data obtained by Forbes et al. (1995) from radar measurements over Obninsk, Russia $\left(54^{\circ} \mathrm{N}, 38^{\circ} \mathrm{E}\right)$ and Saskatoon, Canada $\left(52^{\circ} \mathrm{N}, 107^{\circ} \mathrm{W}\right)$. The variations of the temperature at the middle latitudes of both hemispheres can reach $\pm 5 \mathrm{~K}$.

The response of the model to asymmetric forcing for westward PWs with $m=3$ is shown in Fig. 20. The maximum in this figure is situated at the period 52.5 hours, and this PW can be identified with well known third Rossby-gravity normal atmospheric mode $(3,0)$, the so-called 2-day wave. This result is in a good agreement with the result obtained by Salby (1981a) who obtained the resonant response at the period about 54 hours. The influence of the zonal mean wind on the atmospheric response to the asymmetric low boundary forcing with zonal wave number $m=3$ was considered by Hagan et al. (1993) using GSWM. It has been shown that a relatively weak eastward winter jet and a reversal of the westward jet at lower thermospheric heights in the summer hemisphere can shift the resonant period to about 46 hours and lead to strong increases in the calculated amplitudes of the 2-day PW at tropical to middle summer latitudes. However, it seems that this result is associated with increase of the PW amplitude at the altitude about $70 \mathrm{~km}$ in the summer hemisphere (see figure 6 in Hagan et al., 1993) due to weak numerical instability near the critical surface and does not relate to the resonant atmospheric mode. The reason for this conclusion is that the period of resonant response depends mainly on the zonal mean wind and temperature distributions within the first three atmospheric scale heights (Salby, 1981a) and must be insensitive to changes of background parameters in the upper layers of the atmosphere.

To reproduce the realistic conditions, we calibrate the so-

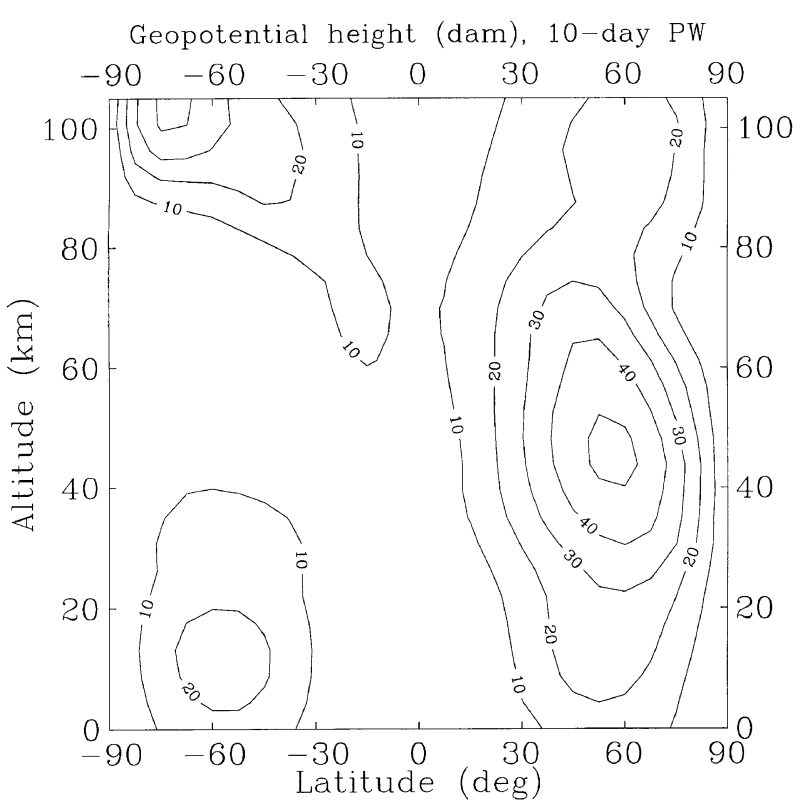

Fig. 15. As in Fig. 14, for the 10-day PW.

Geopotential height, 10-day $\mathrm{PW}, \mathrm{z}=96 \mathrm{~km}$
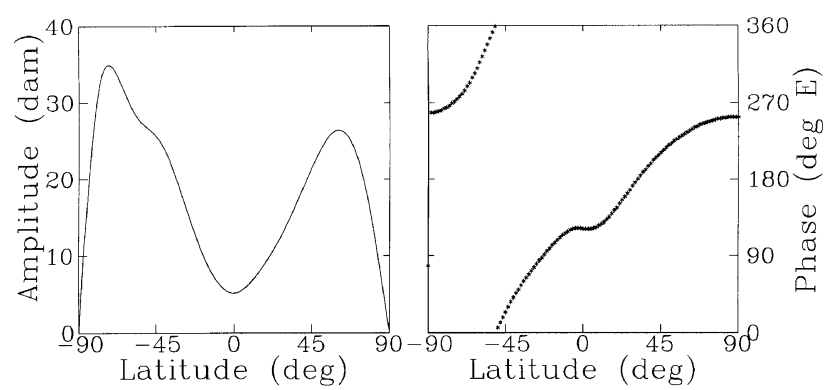

Geopotential height, 16-day PW, $\mathrm{z}=96 \mathrm{~km}$

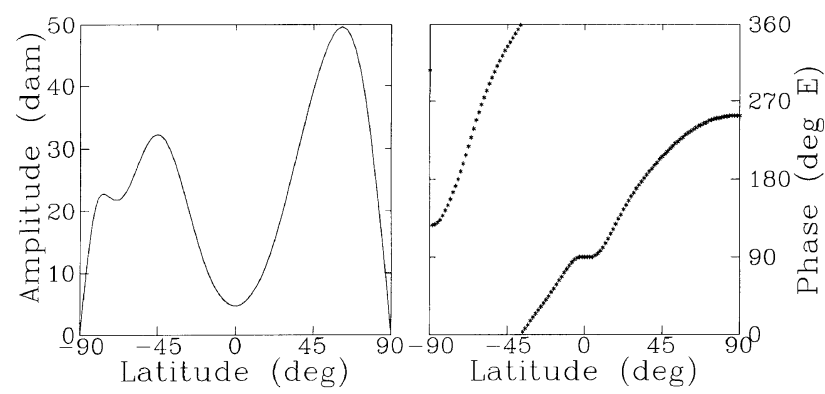

Fig. 16. The latitudinal structure of the geopotential height perturbations in the 10- and 16-day PWs at altitude $96 \mathrm{~km}$.

lution using the observed by WINDII during January 1993 magnitudes of the horizontal wind variations due to the 2-day wave (Ward et al., 1996). The latitudinal structures of the amplitude of zonal and meridional wind perturbations in the 2-day PW at the altitude $z=96 \mathrm{~km}$ are shown in Figs. 21 and 22. Dashed lines show the results obtained from the analysis of WINDII data, solid lines show the numerical solution. One can see that latitudinal structure of the amplitude 


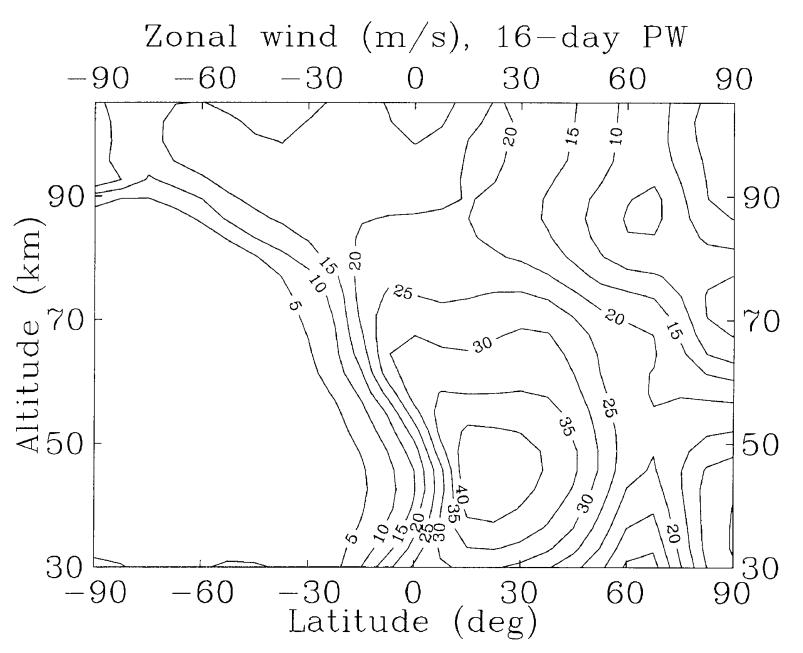

Fig. 17. Latitude-height section of amplitude $(\mathrm{m} / \mathrm{s})$ for the perturbation of zonal wind in 16-day PW.

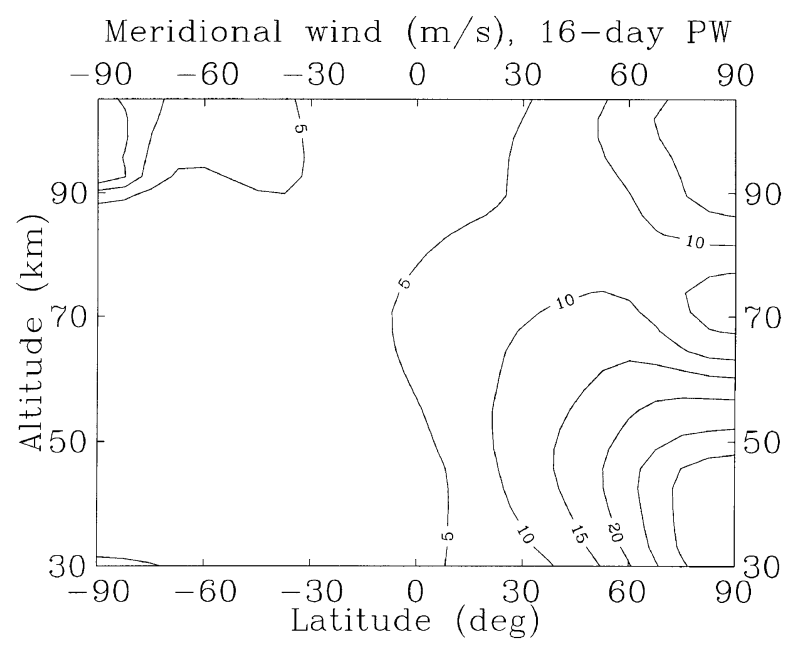

Fig. 18. As in Fig. 17, for the perturbation of meridional wind.

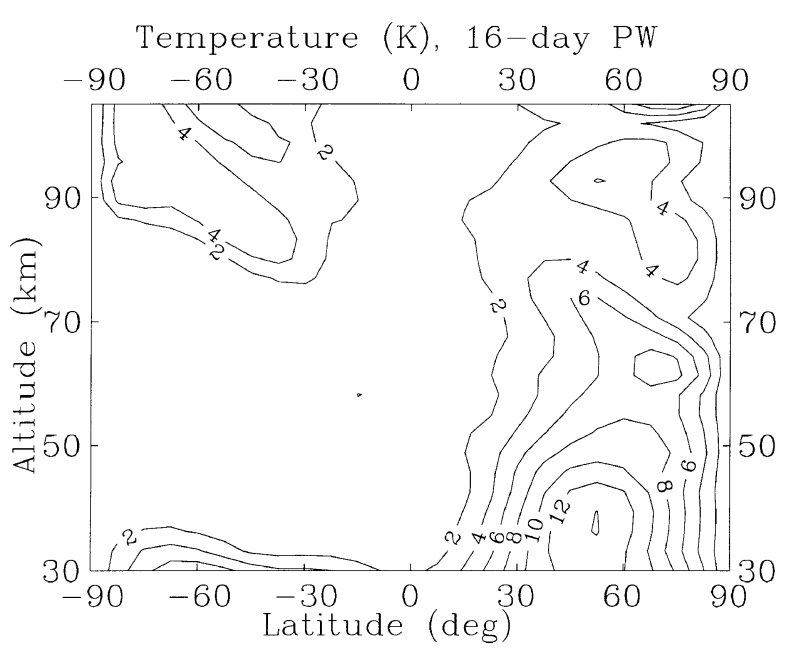

Fig. 19. As in Fig. 17, for the perturbation of temperature.

\section{Asymmetric Forcing $(\mathrm{m}=3)$ \\ Westward modes}

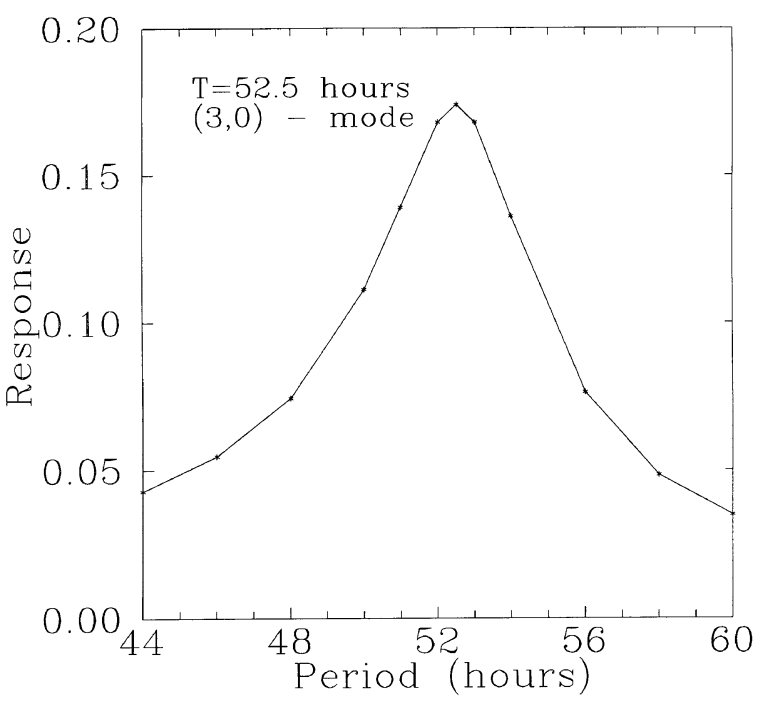

Fig. 20. Response to the asymmetric forcing for the westward PWs with $m=3$.

of the zonal wind does not show good agreement between WINDII results and solution. The latitudinal structure of the PW, and especially the perturbation of the zonal wind, is strongly sensitive to the latitudinal changes in the background wind, and one of the possible reasons of the discrepancy between calculated and observed latitudinal variations of the zonal wind is the smoothing of the background wind in the HWM-93 model. The latitudinal structure of the meridional wind shows good agreement between the WINDII data and solution. The latitude-altitude structure of the amplitude of the meridional wind component in the 2-day PW is shown in Fig. 23. One can see that the 2-day wave propagates from the equatorial stratosphere into the lower thermosphere of the Southern (summer) hemisphere. The results of our calculations show that there is a good agreement between the simulation and observation of meridional wind component in the mesopause region. However, the amplitude of the meridional wind perturbation in the upper stratosphere exceeds 60 $\mathrm{m} / \mathrm{s}$, and this is much larger than the observation. To explain this discrepancy we performed the simulation of the 2-day PW structure using slightly modified zonal mean wind in the equatorial stratosphere, which was defined as follows

$$
\begin{aligned}
\bar{u}= & \bar{u}(\mathrm{HWM}-93) \\
& +20 \exp \left[-\left(\frac{z-45}{15}\right)^{2}\right] \exp \left[-\left(\frac{\varphi}{30}\right)^{2}\right] .
\end{aligned}
$$

It is interesting to note that latitude-height structure of the amplitude of the meridional wind perturbation (Fig. 23) is very similar to the results obtained by Salby (1981b) for the equinox conditions when the westward jet in the lower stratosphere at the low latitudes reverses to the eastward jet in the upper stratosphere. This is the reason to introduce modification (20). The vertical profiles of HWM-93 and modified zonal mean wind over the equator are shown in 
Zonal wind

2-day $P W, z=96 \mathrm{~km}$

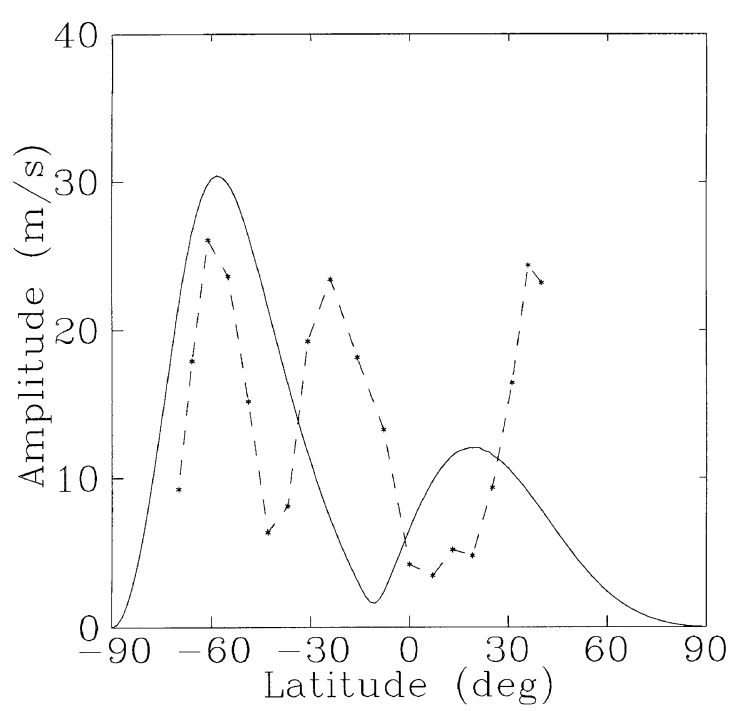

Fig. 21. Latitudinal dependencies of the amplitude and phase of the zonal wind perturbation in 2-day PW with zonal wave number $m=3$ at the altitude $z=96 \mathrm{~km}$. Dashed lines show the results obtained from analysis of WINDII data.

Meridional wind

2-day PW, $\mathrm{z}=96 \mathrm{~km}$

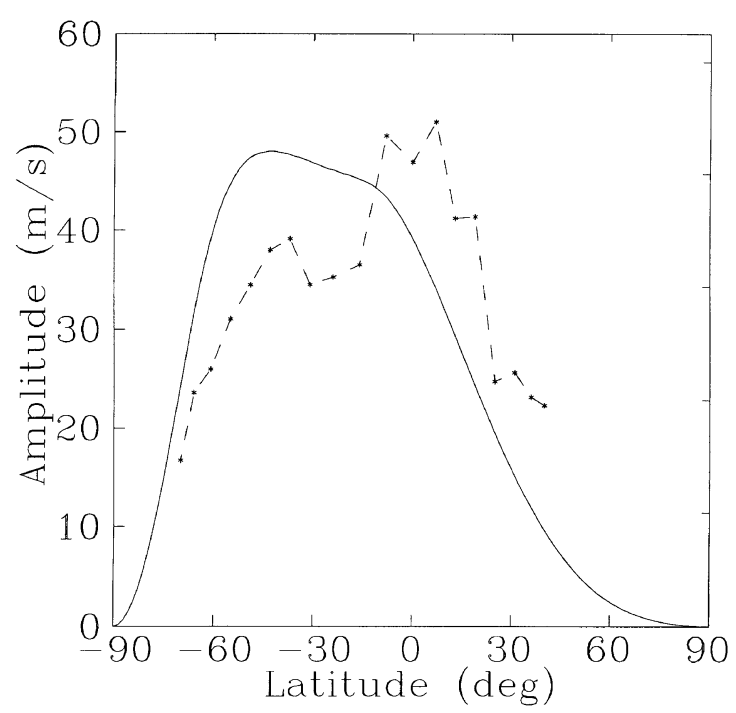

Fig. 22. As in Fig. 21, for the perturbation of meridional wind.

Fig. 24. This figure shows that the modification decreases the positive vertical gradient of the background wind in the upper stratosphere.

The calculated vertical profiles of the amplitude (left) and phase (right) of the meridional wind perturbation over the equator obtained using the HWM-93 and modified zonal mean wind models are shown in Fig. 25. This figure shows that small modification of the background wind in the stratosphere over the equator leads to considerable increase of the

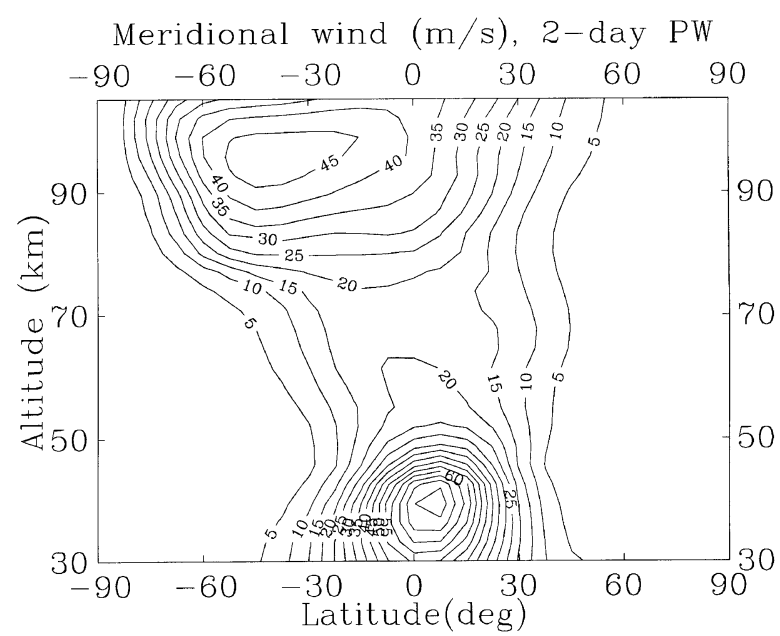

Fig. 23. Latitude-height section of amplitude $(\mathrm{m} / \mathrm{s})$ for the perturbation of the meridional wind component in 2-day PW. HWM-93 zonal mean wind model has been used.

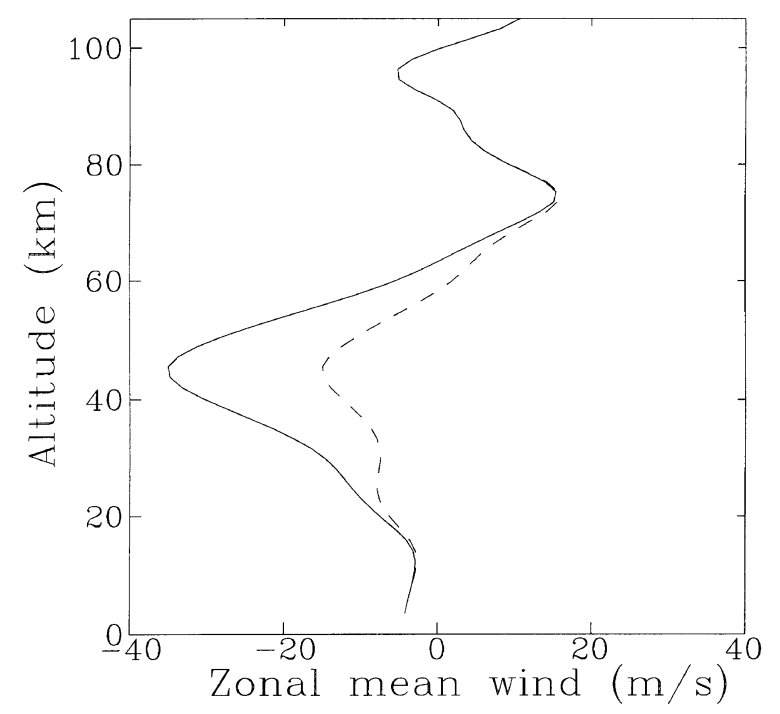

Fig. 24. Vertical profiles of the zonal mean wind over the equator. Solid line shows the HWM-93 model and dashed-modified according Eq. (20).

vertical wave-length in the upper stratosphere (from about 15 to $30 \mathrm{~km}$ ), and to the better propagation of the 2-day PW from the stratosphere into the lower thermosphere. In result the amplitude of the 2-day PW increases in the lower thermosphere and to reach agreement between the amplitude obtained by simulation and the WINDII observations we must recalibrate the solution (divide by factor about 3 ).

Latitude-height section of the amplitude of the meridional wind perturbation obtained after this calibration is shown in Fig. 26. One can see from this figure that discrepancy between the numerical solution and experimental data in the upper stratosphere disappeared. It is necessary to note that the structure of the amplitude of the meridional wind perturbation in the mesopause region practically does not change (compare Figs. 23 and 26). The calculated structures of the 


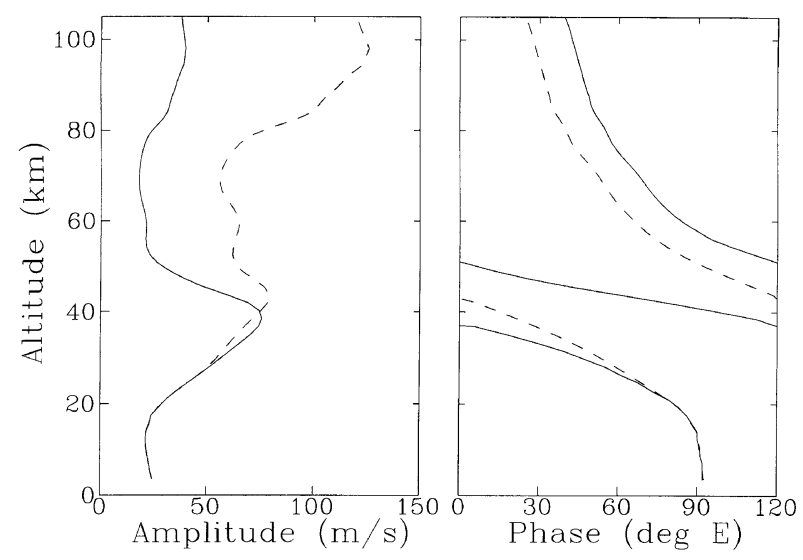

Fig. 25. Vertical profiles of amplitude (left) and phase (right) of the meridional wind perturbation in 2-day PW over the equator obtained using the HWM-93 (solid) and modified (dashed) wind models.

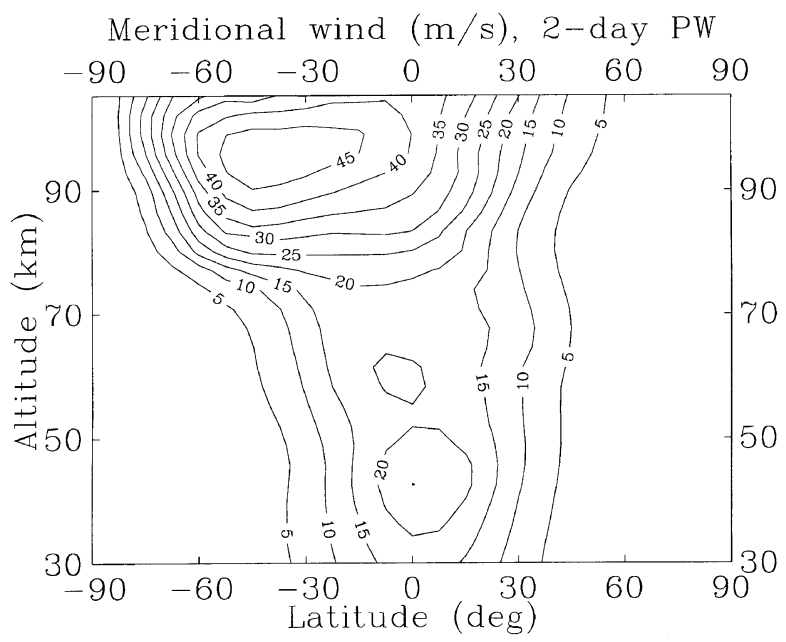

Fig. 26. Latitude-height section of amplitude $(\mathrm{m} / \mathrm{s})$ for the perturbation of the meridional wind component in 2-day PW. Modified zonal mean wind model has been used.

amplitude of zonal wind and temperature perturbations due to the 2-day PW obtained using the modified background wind model are shown in Figs. 27 and 28.

The comparison of results obtained using the HWM-93 and modified zonal mean wind models shows that small variations of the background wind in the stratosphere over the equator (for instance, quasi-biennial oscillations) exert strong influence on the propagation of the 2-day PW from the lower into the upper atmosphere and can modulate the amplitude of this wave in the mesopause region.

\section{The Wave-Mean Flow Interaction}

The generalized Eliassen-Palm theorem states that $\mathbf{F}$ (see (6)) appears as the flux in the wave-activity density conservation law, which can be written for waves of small amplitude $\alpha$ as follows (Andrews and McIntyre, 1976, 1978)

$$
\partial A / \partial t+\nabla \cdot \mathbf{F}=D+O\left(\alpha^{3}\right),
$$

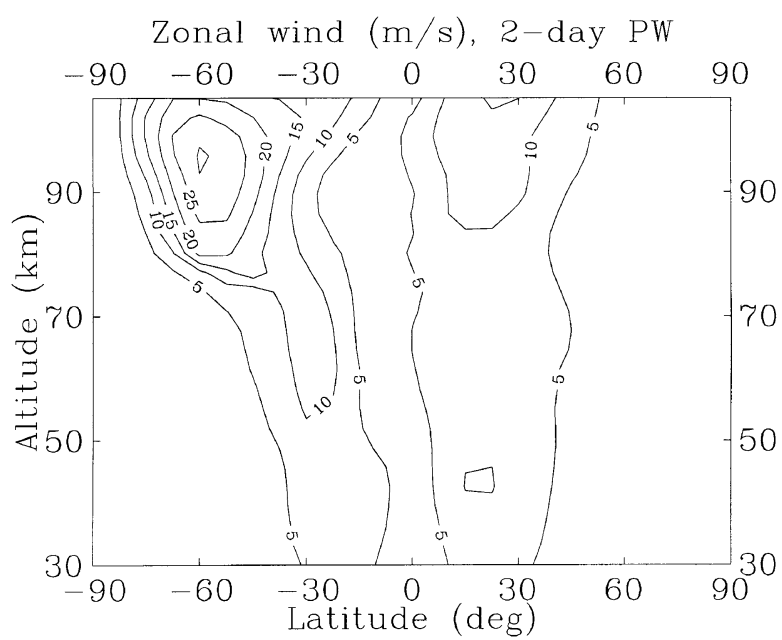

Fig. 27. As in Fig. 26, for the perturbation of zonal wind.

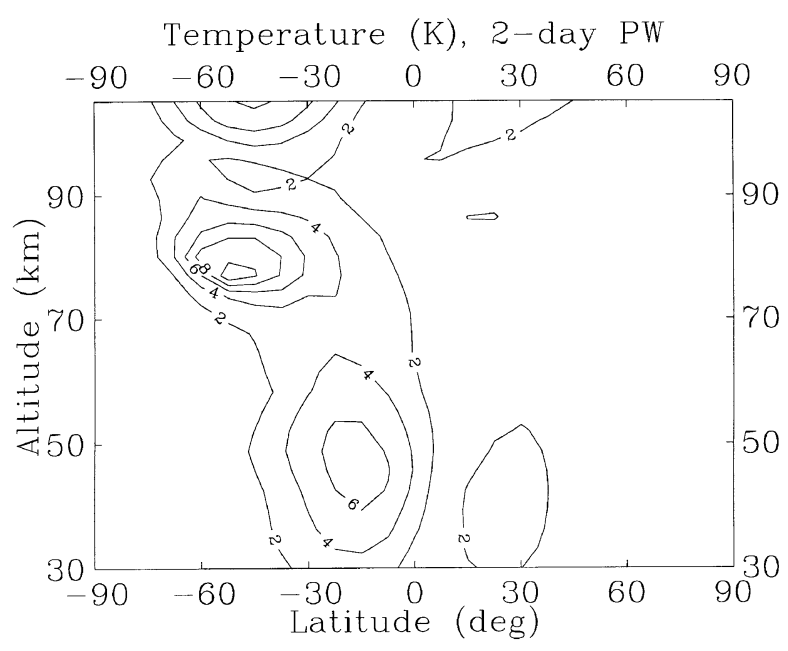

Fig. 28. As in Fig. 26, for the perturbation of temperature.

where $A, D$ and $\mathbf{F}$ are mean $O\left(\alpha^{2}\right)$ functions of wave quantities and $D$ vanishes for conservative (i.e. adiabatic, frictionless) waves. Note that in the case of the steady waves $\nabla \cdot \mathbf{F}=D$. Thus, for the steady non-conservative waves $D \neq 0$ and defines the acceleration of the zonally mean flow by the waves.

Andrews (1987) obtained the simple explicit expressions for the wave-activity density $A$ and non-conservative source of wave-activity $D$, which involve Ertel's potential vorticity, and include only Eulerian quantities

$$
A=\rho_{0} a \cos \varphi\left(A_{1}+A_{2}+A_{3}\right),
$$

$$
\begin{aligned}
A_{1}= & \frac{1}{2} \rho_{0} \overline{\Pi^{\prime 2}} / \bar{J}, \quad A_{2}=\frac{1}{2} \rho_{0}\left(\bar{u}_{z} / \rho_{0}\right)_{z} \overline{\theta^{\prime 2}} / \bar{\theta}_{z}^{2}, \\
A_{3}= & -\overline{u_{z}^{\prime} \theta^{\prime}} / \bar{\theta}_{z}, \\
& D=\rho_{0} a \cos \varphi\left(D_{1}+D_{2}+D_{3}\right),
\end{aligned}
$$

$$
D_{1}=\rho_{0} \overline{\Pi^{\prime} \Sigma^{\prime}} / \bar{J}, \quad D_{2}=\rho_{0}\left(\bar{u}_{z} / \rho_{0}\right)_{z} \overline{\theta^{\prime} Q^{\prime}} / \bar{\theta}_{z}^{2},
$$




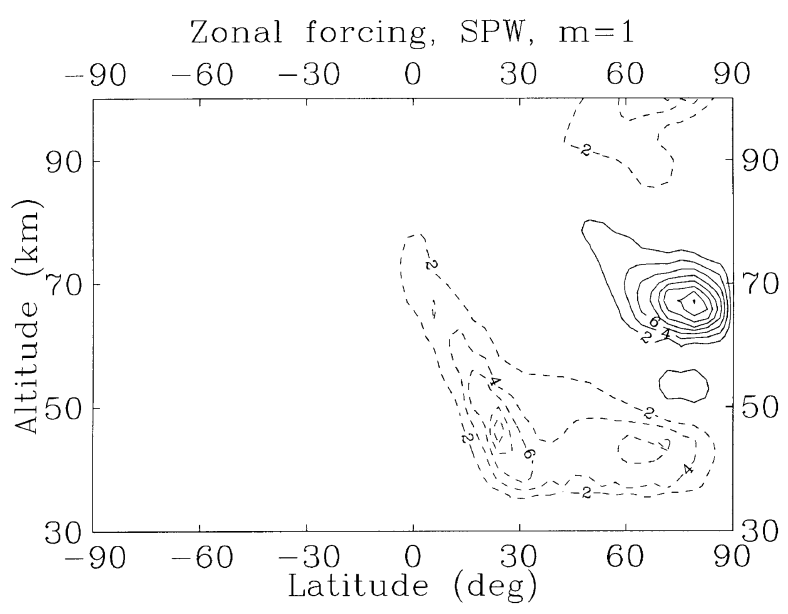

Fig. 29. The force per unit mass on the mean flow $\nabla \cdot \mathbf{F} /\left(\rho_{0} a \cos \varphi\right)$, due to SPW ( $m=1)$ dissipation. Contour interval is $2 \mathrm{~ms}^{-1} \mathrm{day}^{-1}$, solid contours are positive, dashed negative and zero contour is removed.

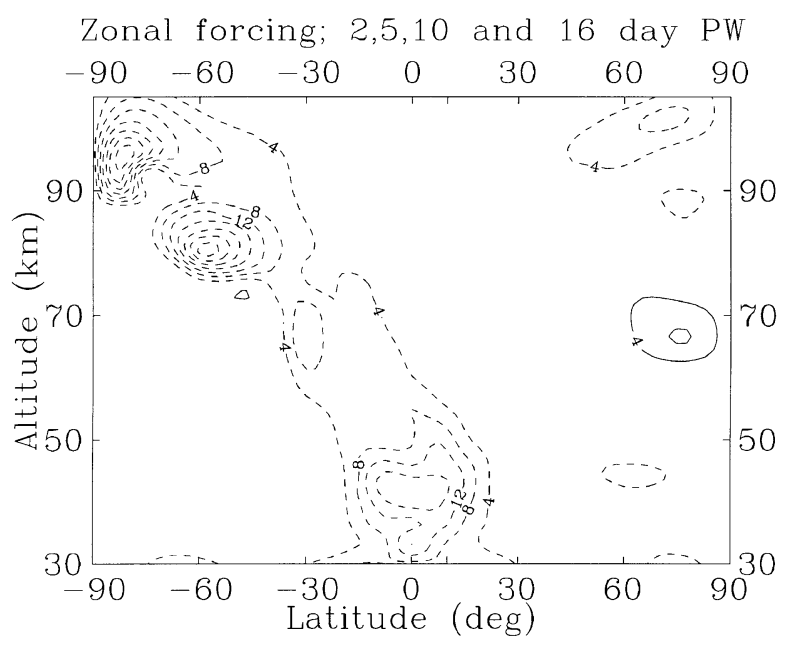

Fig. 30. As in Fig. 29, but for the summary effect of westward traveling 2-, 5-, 10-, and 16-day waves. Contour interval is $4 \mathrm{~ms}^{-1}$ day $^{-1}$.

$$
\begin{aligned}
D_{3} & =-\left(\overline{X_{z}^{\prime} \theta^{\prime}}+\overline{u_{z}^{\prime} Q^{\prime}}\right) / \bar{\theta}_{z}, \\
\Pi^{\prime} & =P^{\prime}-\theta^{\prime} \bar{P}_{z} / \bar{\theta}_{z}, \quad \Sigma^{\prime}=R^{\prime}-Q^{\prime} \bar{P}_{z} / \bar{\theta}_{z}, \\
\bar{J} & =\frac{1}{a} \frac{\partial(\bar{P}, \bar{\theta})}{\partial(\varphi, z)} \equiv \frac{1}{a}\left(\bar{P}_{\varphi} \bar{\theta}_{z}-\bar{P}_{z} \bar{\theta}_{\varphi}\right),
\end{aligned}
$$

where $P$ is Ertel's potential vorticity, and Ertel's theorem states that

$$
D P / D t=R,
$$

where $D / D t$ is the material derivative, and $R$ represents nonconservative effects. The latitude-height section of the EP flux divergence (the force per unit mass on the mean flow due to PWs dissipation) for SPW with $m=1$ are shown in Fig. 29. Our calculations show that in the case of PWs $\left|A_{1}\right| \gg\left|A_{2}\right|,\left|A_{3}\right|\left(\left|D_{1}\right| \gg\left|D_{2}\right|,\left|D_{3}\right|\right)$, and as a consequence of this fact, the sign of the wave-activity density (and EP divergence) is determined by the sign of $\bar{J}$. The sign of $\bar{J}$ is mainly determined by the sign of the latitudinal gradient of the background Ertel's potential vorticity. As a result, in the region of the negative latitudinal gradient of the Ertel's potential vorticity $A<0$ and $D>0$, i.e., we have the eastward acceleration of the zonally averaged flow. The comparison of Fig. 29 with the result obtained by Pogoreltsev (1996) using CIRA-86 mean zonal wind model (Chandra et al., 1990) shows that the background wind distribution is crucial for resulting distribution of the EP flux divergence (see figure 5 in Pogoreltsev, 1996). This strong influence of the zonal mean wind on the force per unit mass on the mean flow due to SPW dissipation can be explained by summary effect of the background wind on the SPW structure and on the distribution of $\bar{J}$.

The magnitudes of the accelerations due to the traveling PWs are comparable with the ones due to SPW with $m=1$. However, if we add together the effects of different westward traveling PWs, the accelerations due to these waves become more significant. In Fig. 30 the force per unit mass on the mean flow due to the 2-, 5-, 10-, and 16-day waves are shown. One can see from this figure that in the mesopause region these accelerations can reach the magnitude about $30 \mathrm{~ms}^{-1} \mathrm{day}^{-1}$. This value is comparable with the accelerations due to the internal gravity waves and atmospheric tides breakdown and/or saturation (Lindzen, 1981).

\section{Main Results}

The results of simulations with the numerical model of the SPW and traveling PWs structure can be formulated as follows

- There is a good qualitative agreement between the results of simulation of the planetary waves and the available experimental data.

- The latitudinal structures of PWs in the middle atmosphere are strongly dependent on the distribution of the background wind, and to provide the detailed comparison of the results of simulation with the characteristics of PWs obtained from experimental data, it is necessary to use (and develop) the background wind models taking into consideration the local latitudinal variations of the zonally averaged wind.

- There is the experimental support (westward slope of the phase) of the cross equatorial propagation of the stationary PWs from the winter stratosphere into the summer lower thermosphere through the westerlies in the low latitude mesosphere, and the question about the existence of eastward zonal wind in this region is crucial for our understanding of the dynamical interaction between hemispheres.

- Small variations of the zonal mean wind in the stratosphere over the equator exert strong influence on the propagation of the 2-day PW from the lower into the upper atmosphere and can modulate the amplitude of this wave in the mesosphere and lower thermosphere.

- Planetary waves can provide the substantial accelerations of the zonally averaged flow in the mesosphere and lower thermosphere so that to simulate the general 
circulation of these regions it is necessary to develop three dimensional models.

- The magnitude of the perturbations of the meteorological parameters due to presence of PWs in the mesopause region is sufficient to be registrated by satellite and ground-based instruments.

Acknowledgments. I acknowledge the time and effort of W. E. Ward and D. Y. Wang who collected and processed the WINDII data used in this paper. I would like to express my thanks to the anonymous reviewers for their helpful comments and criticisms. This work is sponsored in part by EOARD under Special Contract No. SPC-97-4017, and by Grant No. 95-0989 from INTAS-RFBR.

\section{References}

Andrews, D. G., Wave-mean flow interaction in the middle atmosphere, Adv. Geophys., 28A, 244-275, 1985.

Andrews, D. G., On the interpretation of the Eliassen-Palm flux divergence, Q. J. R. Meteorol. Soc., 113, 323-338, 1987.

Andrews, D. G. and M. E. McIntyre, Planetary waves in horizontal and vertical shear: the generalized Eliassen-Palm relation and the zonal acceleration, J. Atmos. Sci., 33, 2031-2053, 1976.

Andrews, D. G. and M. E. McIntyre, Generalized Eliassen-Palm and Charney-Drazin theorems for waves on axisymmetric mean flows in compressible atmosphere, J. Atmos. Sci., 35, 175-185, 1978.

Barnett, J. J. and M. Corney, Planetary waves. Climatological distribution, Handbook for MAP, 16, 86-137, 1985.

Boyd, J. P., The noninteraction of waves with the zonally averaged flow on a spherical Earth and the interrelationships of energy, heat and momentum, J. Atmos. Sci., 33, 2285-2291, 1976.

Chandra, S., E. L. Fleming, M. R. Schoeberl, and J. J. Barnett, Monthly mean global climatology of temperature, wind, geopotential height and pressure for 0-120 km, Adv. Space Res., 10, 2-12, 1990.

Forbes, J. M., M. E. Hagan, S. Miyahara, F. Vial, A. H. Manson, C. E. Meek, and Yu. I. Portnyagin, Quasi 16-day oscillation in the mesosphere and lower thermosphere, J. Geophys. Res., 100, 9149-9163, 1995.

Hagan, M. E., J. M. Forbes, and F. Vial, Numerical investigation of the propagation of the quasi-two-day wave into the lower thermosphere, $J$. Geophys. Res., 98, 23193-23205, 1993.

Hagan, M. E., J. M. Forbes, and F. Vial, On modelling migrating solar tides, Geophys. Res. Lett., 22, 893-896, 1995.

Hedin, A. E., Extension of the MSIS thermosphere model into the middle and lower atmosphere, J. Geophys. Res., 96, 1159-1172, 1991.

Hedin, A. E., M. A. Biondi, R. G. Burnside, G. Hernandez, M. Johnson, T. L. Killen, C. Mazaudier, J. W. Meriwether, J. E. Salah, R. J. Sica, R. W. Smith, N. W. Spencer, V. B. Wikwar, and T. S. Virdi, Revised global model of thermosphere winds using satellite and ground-based observations, J. Geophys. Res., 96, 7657-7688, 1991.

Hedin, A. E., E. L. Fleming, A. H. Manson, F. G. Schmidlin, S. K. Avery, R. R. Clark, S. J. Franke, G. J. Franser, T. Tsuda, F. Vial, and R. A. Vincent, Empirical wind model for the upper, middle and lower atmosphere, $J$. Atmos. Terr. Phys., 58, 1421-1447, 1996.

Kirushov, B. M., Meridional structure of the stationary planetary waves in the middle atmosphere, Trudy Tsent. Aerol. Obs., U.S.S.R., 167, 11-15, 1988 (in Russian).

Kockarts, G., Nitric oxide cooling in the terrestrial thermosphere, Geophys. Res. Lett., 7, 137-140, 1980.

Lieberman, R. S. and D. Reggin, HRDI observations of Kelvin waves in the equatorial mesosphere and lower thermosphere, J. Geophys. Res., 102 26117-26130, 1997.

Lieberman, R. S., M. D. Burrage, D. A. Gell, P. H. Hays, A. R. Marshall, D. A. Ortland, W. R. Skinner, D. Wu, R. A. Vincent, and S. J. Franke, Zonal mean winds in the equatorial mesosphere and lower thermosphere observed by the High Resolution Doppler Imager, Geophys. Res. Lett., 20, 2849-2852, 1993

Lindzen, R. S., Turbulence and stress owing to gravity wave and tidal breakdown, J. Geophys. Res., 86, 9707-9714, 1981.

Lindzen, R. S. and D. Blake, Lamb waves in the presence of realistic distribution of temperature and dissipation, J. Geophys. Res., 77, 2166-2176, 1972.

Longuet-Higgins, M. S., The eigenfunctions of Laplace's tidal equation over a sphere, Phil. Trans. R. Soc. London, 262, 511-607, 1968.

Pogoreltsev, A. I., Simulation of the influence of stationary planetary waves on the zonally averaged circulation of the mesosphere/lower thermosphere region, J. Atmos. Terr. Phys., 58, 901-909, 1996.

Pogoreltsev, A. I. and S. A. Sukhanova, Simulation of the global structure of stationary planetary waves in the mesosphere and lower thermosphere, J. Atmos. Terr. Phys., 55, 33-40, 1993.

Salby, M. L., Global-scale disturbances and dynamic similarity, J. Atmos. Sci., 37, 473-478, 1980.

Salby, M. L., Rossby normal modes in nonuniform background configurations. Part II. Equinox and Solstice conditions, J. Atmos. Sci., 38 , 1827-1840, 1981a.

Salby, M. L., The 2-day wave in the middle atmosphere: observations and theory, J. Geophys. Res., 86, 9654-9660, 1981b.

Schoeberl, M. R. and R. Clark, Resonant planetary waves in a spherical atmosphere, J. Atmos. Sci., 37, 20-28, 1980.

Shepherd, G. G., G. Thuillier, B. H. Solheim, S. Chandra, L. L. Cogger, M. L. Duboin, W. F. J. Evans, R. L. Gattinger, W. A. Gault, M. Herse, A Hauchecorne, C. Lathuilliere, E. J. Llewellyn, R. P. Lowe, H. Teitelbaum, and F. Vial, Longitudinal structure in atomic oxygen concentrations observed with WINDII on UARS, Geophys. Res. Lett., 20, 1303-1306, 1993.

Smith, A. K., Wave transience and wave mean flow interaction caused by the interference of stationary and traveling waves, J. Atmos. Sci., 42, 529-535, 1985.

Smith, A. K., Stationary planetary waves in upper mesospheric winds, $J$. Atmos. Sci., 54, 2129-2145, 1997.

Wang, D. Y., C. McLandress, E. L. Fleming, W. E. Ward, B. Solheim, and G. G. Shepherd, Empirical model of 90-120 km horizontal winds from wind-imaging interferometer green line measurements in 1992-1993, J. Geophys. Res., 102, 6729-6745, 1997.

Ward, W. E., D. Y. Wang, B. H. Solheim, and G. G. Shepherd, Observations of the two-day wave in WINDII data during January, 1993, Geophys. Res. Lett., 23, 2923-2926, 1996.

Zhu, X., Radiative damping revisited: Parameterization of damping rate in the middle atmosphere, J. Atmos. Sci., 50, 3008-3021, 1993.

A. Pogoreltsev (e-mail: pogor@ionos.alma-ata.su) 